\title{
Neurobehavioral Changes of Shipyard Painters Exposed to Mixed Organic Solvents
}

\author{
Choong Ryeol LEE*, Kyoung Sook JEONG, Yangho KIM, \\ Cheol In YOO, Ji Ho LEE and Young Hee CHOI
}

\begin{abstract}
Department of Occupational and Environmental Medicine, Ulsan University Hospital, College of Medicine University of Ulsan 290-3, Jeonha-Dong, Dong-Gu, Ulsan, 682-714, South Korea
\end{abstract}

Received July 12, 2004 and accepted February 1, 2005

\begin{abstract}
This study was conducted to evaluate neurobehavioral changes arising from occupational exposure to organic solvents among shipyard painters and to establish whether a dose-effect relation existed where there was any observed impairment of neurobehavioral performance by running the test of Simple Reaction Time (SRT), Symbol Digit Substitution (SD), and Finger Tapping Speed (FT) with a computer-assisted neurobehavioral test battery. The study group consisted of 180 shipyard painters and 60 reference workers. The workers answered a self-administered questionnaire on occupational, medical history, and demographic characteristics including age, work duration, education level, and quantity and frequency of alcohol and smoking, and performed three psychometric tests on the Korean Computerized Neurobehavioral tests. To estimate cumulative exposure level, samples of ambient air on 61 painters were analyzed using a gas chromatograph. Shipyard painters and the reference group showed significant differences in the results of test of SD, FT of dominant hand, and FT of non-dominant hand. The test results of SD of shipyard painters also showed significant difference by duration of work. This suggests that occupational exposure of organic solvent could induce neurobehavioral changes in the shipyard painters. Therefore an objective neurobehavioral test is recommended on evaluating neurobehavioral performance of longterm solvent-exposed shipyard workers.
\end{abstract}

Key words: Computer assisted neurobehavioral test, Shipyard painter, Organic solvents

\section{Introduction}

There is considerable evidence that long term occupational exposure to mixed organic solvents can cause a wide range of chronic central nervous system abnormalities ${ }^{1-8)}$. Behavioral manifestations of such damage include an increase in psychiatric symptoms, reported memory and concentration difficulties, and impairment of cognitive functioning as demonstrated by performance on neurobehavioral tests. In many cases these effects are subtle, occurring in the absence of overt clinical signs and only measurable by use of psychological test procedures.

There are many neurobehavioral tests and systems to assess

*To whom correspondence should be addressed. neurotoxic exposures in the workplace. World health organization (WHO) recommended neurobehavioral core test battery (NCTB) which consisted of digit symbol, digit span, Benton visual retention, pursuit aiming, simple reaction time, Santa Ana, and profile of mood states ${ }^{9,10)}$. Letz and Baker developed the neurobehavioral evaluation system (NES) in the mid $1980 \mathrm{~s}^{11)}$. The NES is a computer based testing system that incorporates the cognitive tests from NCTB and a number of other tests used in clinical neuropsychology. Letz's subsequent adaptation of the battery (the NES II) became the dominant testing system in $1990 \mathrm{~s}^{12,13)}$. Iregren et al. ${ }^{14)}$ developed Swedish performance evaluation system (SPES), which was used for screening test for neurobehavioral disturbances of some neurotoxins ${ }^{15-18)}$. Recently, the behavioral assessment and research system (BARS) was used 
for the detection of neurotoxicity in non-mainstream human populations specifically people with limited education or literacy ${ }^{19-21)}$.

The shipyard painters are exposed to many kinds of organic solvents and other neurotoxin such as lead which may be harmful to nervous system. In 1985 Valciukas et al. ${ }^{22)}$ reported that neurobehavioral performance decreased in the shipyard painters compared with a control group, and found no significant correlations between performance test scores and duration of solvent exposure. In a study by Ruijten et $a l .{ }^{23)}$, long-term exposure to xylene and other mixed organic solvents in shipyard spray painters caused impairment of simple visuo-motor performance and complex perceptual coding, and a relationship between effects on perceptual coding and the exposure index was demonstrated. Prevalence of neuropsychological symptoms among a cohort of dockyard painters was significantly increased compared with a nonpainters $^{24,25)}$.

When planning human neurobehavioral research to detect exposure effects, the primary factor should be the chemicals to which the target subject is exposed. However, it is well known that Iregren and Letz's recommendation of the symbol digit, Simple Reaction Time, and tapping tests should be included in the core set of neurobehavioral tests ${ }^{16}$.

In Korea, Korean version of SPES (KCN; Korean Computerized Neuro-behavioral System version 2.1, ZNCSoft, Korea) has been widely used to detect neurobehavioral disturbance of workers exposed to various neurotoxin such as organic solvent and manganese ${ }^{26-28)}$. Korean version of SPES consists of Korean written instruction and a simplified keyboard that have 10 buttons and several symbol keys (Fig. 1). We selected 3 tests from the Korean version of SPES to evaluate neurobehavioral performance of shipyard painters: Simple Reaction Time (SRT), Symbol Digit Substitution (SD), and Finger Tapping Speed (FT) in the battery were administered.

The objectives of the present study is to investigate neurobehavioral changes of shipyard painters compared with workers without organic solvent exposure, and to establish whether a dose-effect relation existed in where there was any observed impairment of neurobehavioral performance with a computer-assisted neurobehavioral test battery.

\section{Subjects and Methods}

The exposed subjects comprised 180 shipyard painters employed by a shipyard in Ulsan, Korea. There were 60 groups that consisted of 3 cases whose ages were close to 1 randomly selected safety inspector who did not exposed to

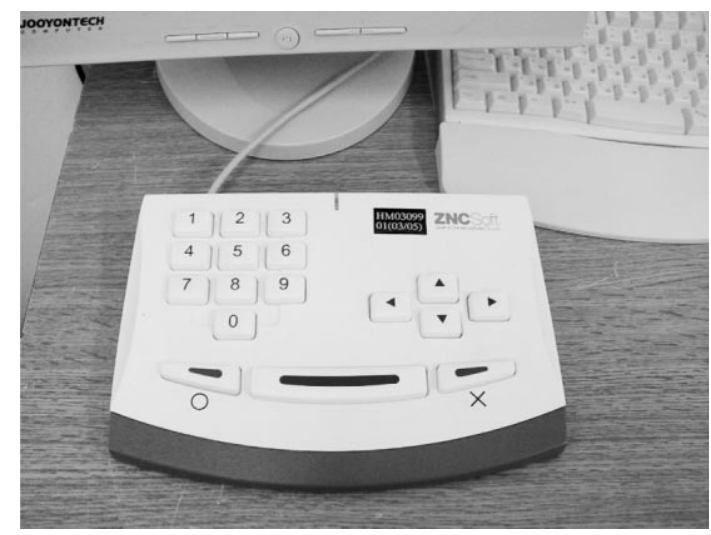

Fig. 1. Keyboard of Korean version of Swedish performance evaluation system.

organic solvent in a shipyard. The painters were exposed to mixed organic solvents during their working of spray painting, mixing of paint, and painting by brush. The study subjects represented $51 \%$ of all those painters employed by a shipyard. Twenty-six percent were unwilling to take part in the study and $23 \%$ were excluded due to pre-set exclusion criteria, namely educational level below $9 \mathrm{yr}$, previous head injury, alcohol or drug dependency, or existing disease affecting the nervous system. The painters included in exposure group did not change the job duties up to the study. The study was carried out with their informed consent.

A questionnaire was administered prior to testing. The questionnaire consisted of occupational, medical history, and demographic characteristics including age, work duration, education level, and quantity and frequency of alcohol and smoking. All the exposed subjects had an exposure-free time of at least $48 \mathrm{~h}$. Before a test day, the subjects were asked to sleep their usual duration and not to drink any alcoholic beverages in the evening before the test day. The subjects were given the amount of US $\$ 35$ (approximately $120 \%$ of their wage for working an equivalent time) as an incentive. A trained examiner administered the test of Simple Reaction Time, Symbol Digit Substitution, and Finger Tapping Speed in the battery.

Simple Reaction Time is a visuo-motor speed test that measures how fast a subject responds to a visual stimulus by pressing a button ${ }^{29}$. Data are recorded as individual reaction times over the presentation of nine blocks of 8 trials each. The time interval between the blocks is $30 \mathrm{~s}$. The mean and standard deviation of the response latencies (in msec) over the last 6 blocks are used as the dependent measures for this task. Shorter reaction time indicates better neuropsychological performance. Symbol Digit Substitution 
Table 1. Demographic characteristics of the shipyard painters and controls

\begin{tabular}{lccr}
\hline Characteristics & Painters $(\mathrm{n}=180)$ & Controls $(\mathrm{n}=60)$ & $\mathrm{p}$ \\
\hline Age $(\mathrm{yr})$ & $43.9 \pm 8.0$ & $44.0 \pm 6.2$ & 0.920 \\
$30-39$ & $54(30.0 \%)$ & $18(30.0 \%)$ & \\
$40-49$ & $96(53.3 \%)$ & $32(53.3 \%)$ & \\
$50-59$ & $30(16.7 \%)$ & $10(16.7 \%)$ & \\
Education (yr) & $12.6 \pm 2.9$ & $13.9 \pm 2.0$ & 0.000 \\
Work duration (yr) & $16.5 \pm 9.0$ & $16.1 \pm 10.5$ & 0.775 \\
Smoking (Pack $\cdot \mathrm{yr})$ & $12.9 \pm 9.8$ & $13.0 \pm 16.1$ & 0.964 \\
Absolute alcohol consumption $(\mathrm{g} / \mathrm{wk})$ & $86.5 \pm 110.4$ & $84.0 \pm 133.8$ & 0.896 \\
\hline
\end{tabular}

is widely used and sensitive tests to detect central nervous system damage regardless of its etiology in human behavioral neurotoxicity research ${ }^{30}$. The test presents nine symbols, each paired with a number between 1 and 9 in matrix. After five presentations of the symbols and digits together, the symbols are presented alone and a subject asks to respond with corresponding digits. Mean response latency (in sec) is recorded. A shorter latency indicates better neurological performance. This test is a measure of incidental memory and is recorded in terms of number of incorrect responses. Finger Tapping Speed test is a test of motor speed and coordination $^{29)}$. An examinee is instructed to press a button as many as possible in $30 \mathrm{~s}$. This occurs with the dominant hand and subsequently the non-dominant hand.

For exposure assessment two sources of information were used. One is a direct field exposure measurement, and the other is information from job descriptions included in the questionnaire. The direct field exposure measurement was done in April 2003. Randomly selected 61 out of 180 shipyard painters were given three passive dosimeters (3M 3500 Organic vapor Monitors) to collect volatile organic compounds in the personal breathing zone during 3 separate work days. Subjects were instructed to attach the dosimeters to the lapel or pocket of their shirt taking care that the dosimeter was exposed to the air all the times. The dosimeter were analyzed by NIOSH Method 1500 for hydrocarbon extraction from charcoal using $1.5 \mathrm{ml}$ of carbon disulfide containing $50 \mu \mathrm{g} / \mathrm{ml}$ of bromofluorobenzene as an internal standard. The samples were analyzed by gas chromatography HP 5890II mass (Hewlett Packard, USA) and gas chromatography mass spectrometry HP6890/5973N (Hewlett Packard, USA). Mixed organic solvent exposure index (En) was a sum of each current solvent level divided the threshold limit value (TLV) of the American Conference of Governmental Industrial Hygienists (ACGIH) ${ }^{31}$.

$\mathrm{En}=\Sigma \mathrm{Ci} / \mathrm{TLVi}$, where $\mathrm{Ci}=$ concentration of each solvent, $\mathrm{TLV} i=\mathrm{TLV}$ of each solvent
A cumulative exposure index (CEI) was calculated from: a sum of the products of exposure duration and mixed solvent exposure index. Exposure duration was working duration of painting job expressed in years.

$\mathrm{CEI}=\mathrm{En} \times$ exposure duration (year)

Exposure duration in years was once more used as a surrogate for dose. The subjects were structured into 3 exposure groups $(<10 \mathrm{yr}, 10-20 \mathrm{yr},>20 \mathrm{yr})$.

Data were analyzed by SPSS 10.0 for Windows. Student $t$-test was used for a simple comparison of the neurobehavioral performance between the exposed and control groups. To ascertain and control of confounding factors multiple regression analysis and the analysis of covariance were used.

The demographic data revealed no significant difference between the shipyard painters and controls on the demographic variables except education level. The mean age of shipyard painters was 43.9 , and that of control was 44.0. The control group had more educated than shipyard painters $(p=0.000)$. The mean work duration of shipyard painters was $16.5 \mathrm{yr}$, and that of controls was $16.1 \mathrm{yr}$ (Table 1).

Xylene, methyl isobutyl ketone (MIBK), ethylbenzene, 1-butanol, 2-methoxyethanol, cyclohexane, trimethylbenzene, toluene, and other several organic solvents were detected. The airborne concentrations of top 10 organic solvents were listed in Table 2.

The concentrations of all organic solvents were below their TLVs of ACGIH.

\section{Results}

Multiple regression analysis was performed to assess the effect of the demographic characteristics on neurobehavioral performance. Independent variables comprised exposure, age, duration of education, alcohol intake amount (ethanol $\mathrm{g} / \mathrm{wk}$ ), and tobacco smoking amount (packs/yr). Exposure 
Table 2. Airborne concentrations (ppm) of top 10 organic solvents

\begin{tabular}{lrccr}
\hline & GM & GSD & Range & TLV \\
\hline Xylene & 22.70 & 4.10 & $1.6-591.2$ & 100 \\
MIBK & 10.04 & 3.09 & $1.0-404.2$ & 50 \\
Ethylbenzene & 8.26 & 3.54 & ND -160.8 & 100 \\
1-Butanol & 7.34 & 4.41 & $0.3-154.5$ & 50 \\
2-Methoxyethanol & 6.43 & 2.90 & $0.4-85.2$ & 100 \\
Cyclohexanone & 5.78 & 7.59 & $0.2-182.9$ & 300 \\
Trimethylbenzene & 3.71 & 3.95 & $0.2-57.0$ & 15 \\
Toluene & 3.70 & 2.75 & ND-58.0 & 100 \\
N-Butylacetate & 3.30 & 4.67 & ND-160.8 & 150 \\
2-Butoxyethanol & 1.25 & 1.73 & $0.6-2.6$ & 25 \\
\hline
\end{tabular}

GM: geometric mean, GSD: geometric standard deviation, ND: not detected, TLV: threshold limit value.

Table 3. Multiple regression analysis of neurobehavioral tests $(n=240)$

\begin{tabular}{|c|c|c|c|c|c|c|c|c|c|c|c|c|}
\hline \multirow{2}{*}{ Variable } & \multicolumn{3}{|c|}{ SRT } & \multicolumn{3}{|c|}{ SD } & \multicolumn{3}{|c|}{ FTSD } & \multicolumn{3}{|c|}{ FFTSN } \\
\hline & $\beta$ & $\mathrm{p}$ & $\mathrm{R}^{2}$ & $\beta$ & $\mathrm{p}$ & $\mathrm{R}^{2}$ & $\beta$ & $\mathrm{p}$ & $\mathrm{R}^{2}$ & $\beta$ & $\mathrm{p}$ & $\mathrm{R}^{2}$ \\
\hline Exposure & -3.98 & 0.742 & & -524.43 & 0.0000 & & 3.09 & 0.145 & & 3.64 & 0.000 & \\
\hline Age (yr) & -0.55 & 0.432 & & 26.52 & 0.000 & & -0.20 & 0.000 & & -0.08 & 0.0301 & \\
\hline Education (yr) & -0.49 & 0.415 & 0.016 & -413.31 & 0.000 & 0.178 & -0.07 & 0.317 & 0.093 & -0.02 & 0.122 & 0.162 \\
\hline Smoking & 0.72 & 0.137 & & 2.43 & 0.677 & & -0.02 & 0.666 & & -0.05 & 0.354 & \\
\hline Alcohol & -0.05 & 0.313 & & -0.34 & 0.546 & & -0.01 & 0.085 & & -0.01 & 0.091 & \\
\hline Constant & 319.8 & 0.000 & & 2591.75 & 0.000 & & 67.81 & 0.000 & & 55.55 & 0.000 & \\
\hline
\end{tabular}

$\beta$ : regression coefficient, SRT: Simple Reaction Time, SD: Symbol Digit Substitution, FTSD: Finger Tapping Speed of dominant hand, FTSN: Finger Tapping Speed of non-dominant hand.

Table 4. Results of neurobehavioral test of study subjects before and after controlling age and education

\begin{tabular}{|c|c|c|c|c|c|c|}
\hline \multirow{2}{*}{ Tests } & \multicolumn{3}{|c|}{ Unadjusted mean \pm S.D. } & \multicolumn{3}{|c|}{ Adjusted mean (S.E.) } \\
\hline & Painters $(n=180)$ & Controls $(n=60)$ & $\mathrm{p}$ & Painters $(n=180)$ & Controls $(n=60)$ & $\mathrm{p}$ \\
\hline SRT (msec) & $297.2 \pm 70.0$ & $292.2 \pm 95.0$ & 0.671 & $296.0(5.9)$ & $295.8(10.9)$ & 0.992 \\
\hline $\mathrm{SD}(\mathrm{msec})$ & $3,233.2 \pm 998.9$ & $2,693.8 \pm 711.8$ & 0.000 & $3,156.6(67.7)$ & $2,691.6(124.3)$ & 0.000 \\
\hline FTSD (No. of taps/10 sec) & $62.6 \pm 8.2$ & $66.4 \pm 9.7$ & 0.000 & $63.0(0.6)$ & $65.5(1.2)$ & 0.046 \\
\hline FTSN (No. of taps/10 sec) & $55.9 \pm 8.0$ & $60.2 \pm 9.7$ & 0.000 & $56.1(0.7)$ & $60.3(1.2)$ & 0.003 \\
\hline
\end{tabular}

S.D.: standard deviation, S.E.: standard error, SRT: Simple Reaction Time, SD: Symbol Digit Substitution, FTSD: Finger Tapping Speed of dominant hand, FTSN: Finger Tapping Speed of non-dominant hand.

group had a significant effect on the results of SD and FT of non-dominant hand. Age had a significant effect on those of SD and FT of dominant hand. However duration of education had a significant effect only on the result of SD. On the contrary alcohol intake amount and tobacco smoking amount did not affect any neurobehavioral performance (Table 3).

Simple comparison of the results of neurobehavioral performance between shipyard painters and controls showed significant differences in the tests of SD, FT of dominant hand, and FT of non-dominant hand. These significant differences between groups were sustained though significance levels became slightly week despite controlling the confounding factor such as age and education level by the analysis of covariance (Table 4).

In another multiple regression analysis all results of neurobehavioral performance were not affected by cumulative solvent exposure index obtained by the direct 
Table 5. Results of neurobehavioral test of shipyard painters by duration of work adjusted for age and education

\begin{tabular}{lccc}
\hline Tests & $<10 \mathrm{yr}(\mathrm{n}=48)$ & $10-20 \mathrm{yr}(\mathrm{n}=41)$ & $>20 \mathrm{yr}(\mathrm{n}=91)$ \\
\hline SRT $(\mathrm{msec})$ & $297.8(20.4)$ & $297.9(11.2)$ & $292.3(11.6)$ \\
SD (msec) & $2,972.1(282.5)$ & $3,033.8(155.1)$ & $3,452.4(160.7)^{*}$ \\
FTSD (No. of taps/10sec) & $64.8(2.3)$ & $63.9(1.3)$ & $61.3(1.3)^{\#}$ \\
FTSN (No. of taps/10 sec) & $57.6(2.4)$ & $56.3(1.3)$ & $55.2(1.3)$ \\
\hline
\end{tabular}

*; $\mathrm{P}<0.05$, \#; $\mathrm{P}=0.052$, S.E.: standard error, SRT: Simple Reaction Time, SD: Symbol Digit Substitution, FTSD: Finger Tapping Speed of dominant hand, FTSN: Finger Tapping Speed of non-dominant hand.

field exposure measurement of current exposure and duration of exposure (The result of tests was not presented).

However, when 'duration of exposure in year' was used as a measure of 'dose', the test results of SD between the group with exposure years $<10$ and the group with exposure years $>20$ were significantly different after controlling for age and education level by the analysis of covariance. Those of FT of dominant hand were different between the two groups through not significantly (Table 5).

\section{Discussion}

During the last two decades, the use of computers in psychological testing has steadily increased, motivated by the ambition to reach higher levels of resource efficiency and a higher degree of uniformity in test administration and scoring than is possible with traditional procedures. Computer-assisted systems also have been developed to provide interpretive test reports. The combination of computer and psychological tests has led to a compilation of systems with automatic test interpretation.

Iregren and Letz recommended that the core set of tests should include the symbol digit, Simple Reaction Time, and finger tapping tests ${ }^{16}$. So we adopted 3 tests of KCN to assess the neurobehavioral performance of shipyard painters.

Age is the strongest factor of neurobehavioral performance $^{1,29,32,33)}$. To remove the effect of age on neurobehavioral performance we matched age of painters and controls. As duration of education also was known to affect neurobehavioral performance ${ }^{9,29,32,34)}$, we excluded workers whose educational level was below $9 \mathrm{yr}$ to reduce the effect of education level on neurobehavioral performance. However, duration of education still had effect on the result of SD according to the results of multiple regression analysis in our study.

The results of our study are consistent with the previous studies of Valciukas et al..$^{22)}$ and Ruijten et al. ${ }^{23)}$ who reported neurobehavioral changes of shipyard painters. However, we can find no significant correlations between neurobehavioral performance and cumulative exposure index. Considering of the test results of neurobehavioral performance, damage of central nervous system with or without abnormal motor speed and coordination was suspected in shipyard painters who were chronically exposed to mixed organic solvents.

Alcohol intake amount did not affect any of neurobehavioral performance, this was consistent with the previous study of Paker et al. ${ }^{35)}$. Tobacco smoking amount also did not affect any of neurobehavioral performance, this was consistent with the study of Andersson and Hockey ${ }^{36)}$.

Affinity to computer was known to affect the results of neurobehavioral test ${ }^{37)}$, so we used a simplified keyboard that had 10 buttons and several symbol keys to reduce the effect of affinity to computer. This keyboard was proved to be suitable all kinds of subjects regardless of familiarity to computer on the performance of computerized neurobehavioral tests ${ }^{38}$.

The shipyard painters were exposed to mixed organic solvents such as xylene, MIBK, ethylbenzene and so on, the geometric concentrations of each organic solvent were below TLVs of ACGIH. At first we used cumulative exposure index as 'dose' of organic solvents, however, there was no correlation between cumulative exposure index and neurobehavioral performance. It means cumulative exposure index is not a suitable measure of chronic exposure effect of organic solvents on neurobehavioral performance, but a measure of current exposure, and cumulative exposure index also did not reflect the extent of internal dose of current and past exposure that could have a biological effect on the exposed workers. A direct field measurement is useful only for identifying the kinds and levels of organic solvents for this study. As Spurgeon et al ${ }^{39)}$ have used exposure duration as 'dose' of exposure, the painters were structured into 3 exposure groups $(<10 \mathrm{yr}, 10-20 \mathrm{yr},>20 \mathrm{yr})$. The test results 
of SD between the group with exposure years $<10$ and the group with exposure years $>20$ were significantly different after controlling the confounding factors by the analysis of covariance. Though the significance level was slightly low, those of FT of dominant hand were also different between the group with exposure years $<10$ and the group with exposure years $>20$. These means there is a week doseeffect of organic solvents on neurobehavioral performance.

Certain limitations exist with this study. First, we performed only 3 tests of KCN, so we could not evaluate various functions of central nervous system. Second, we did not consider the effects of other neurotoxic substance that could be exposed during working such as lead. The possibility of neurobehavioral changes due to lead could not be rule out.

In summary, occupational exposure of organic solvent could induce neurobehavioral changes in the shipyard painters. Therefore an objective neurobehavioral test is recommended on evaluating neurobehavioral performance of long-term solvent-exposed shipyard workers.

\section{References}

1) Elofsson $S$, Gamberale F, Hindmarsh $T$, Iregren $A$, Isaksson A (1980) Exposure to organic solvents-A cross section epidemiologic investigation on occupationally exposed car and industrial spray painter with special reference to the nervous system. Scan J Work Environ Health 6, 239-73.

2) Morrow LA, Ryan CM, Hodgson MJ, Robin N (1990) Alterations in cognitive and psychological functioning after organic solvent exposure. J Occup Med 32, 44450.

3) Bleecker ML, Bolla KI, Agnew J, Schwartz BS, Ford DP (1991) Dose-related subclinical neurobehavioral effects of chronic exposure to low levels of organic solvents. Am J Ind Med 19, 715-28.

4) Kishi R, Harabuchi I, Katakura Y, Ikeda T, Miyake H (1993) Neurobehavioral effects of chronic occupational exposure to organic solvents among Japanese industrial painters. Environ Res 62, 303-13.

5) Grosch JW, Neale AV, Demers RT (1996) Neurobehavioral and health-related deficits in solventexposed painters. Am J Ind Med 6, 623-32.

6) Ellingsen DG, Lorentzen P, Langard S (1997) A neuropsychological study of patients exposed to organic solvents. Int J Occup Environ Health 3, 177-83.

7) Chen R, Wei L, Seaton A (1999) Neuropsychological symptoms in Chinese male and female painters: an epidemiological study in dockyard workers. Occup Environ Med 56, 388-90.

8) Fiedler N, Weisel C, Lynch R, Kelly-McNeil K, Wedeen R, Jones K, Udasin I, Ohman-Strickland P, Gochfeld M (2003) Cognitive effects of chronic exposure to lead and solvents. Am J Ind Med 44, 413-23.

9) Anger WK, Cassitto MG, Liang YX, Amador R, Hooisma J, Chrislip DW, Mergler D, Keifer M, Hortnagl J, Fournier L (1993) Comparison of performance from three continents of the WHO-recommended neurobehavioral core test battery. Environ Res 62, 12547.

10) Lee DH, Park IG, Kim JH, Lee YH, Kim D, Kang SK (1998) Neurobehavioral changes in shoe manufacturing workers. Neurotoxicol Teratol 20, 259-63.

11) Baker EL, Letz R, Fidler AT (1985) A computer-based neurobehavioral evaluation system for occupational and environmental epidemiology: methodology and validation studies. Neurobehav Toxicol Teratol 7, 36977.

12) Krieg EF, Chrislip DW, Letz R, Otto DA, Crespo CJ, Brightwell WS, Ehrenberg RL (2001) Neurobehavioral test performance in the third National Health and Nutrition Examination Survey. Neurotoxicol Teratol 23, 569-89.

13) Proctor SP, Letz R, White RF (2000) Validity of a computer-assisted neurobehavioral test battery in toxicant encephalopathy. NeuroToxicol 21, 703-14.

14) Iregren A (1990) Psychological test performance in foundry workers exposed low levels of manganese. Neurotoxicol Teratol 12, 673-5.

15) Iregren A, Gambrale F (1990) Human behavioral toxicology-Central nervous effects of low-dose exposure to neurotoxic substances in the work environment. Scand J Work Environ Health 16 (Suppl 1), 17-25.

16) Iregren A, Letz $R$ (1992) Computerized testing in neurobehavioral toxicology. Appl Psychol 41, 247-55.

17) Iregren A, Gamberale F, Kjellberg A (1996) SPES: a psychological test system to diagnose environmental hazards. Neurotoxicol Teratol 18, 485-91.

18) Mergler $D$, Huel G, Bowler R, Iregren $A$, Belanger $S$, Baldwin M, Tardif R, Smargiassi A, Martin L (1994) Nervous system dysfunction among workers with longterm exposure to manganese. Environ Res 64, 15180.

19) Rohlman DS, Sizemore OJ, Anger WK, Kovera CA (1996) Computerized neurobehavioral testing: techniques for improving test instructions. Neurotoxicol 
Teratol 18, 407-12.

20) Rohlman DS, Bailey SR, Brown M, Blanock M, Anger WK, McCauley L (2000) Establishing stable test performance in tests from the Behavioral Assessment and Research System (BARS). Neurotoxicol 21, 71523.

21) Rohlman DS, Gimenes LS, Eckerman DA, Kang SK, Farahat FM (2003) Development of the Behavioral Assessment and Research System(BARS) to detect and characterize neurotoxicity in humans. Neurotoxicol 24, 523-31.

22) Valciukas JA, Lilis R, Singer RM, Glickman L, Nicholson WJ (1985) Neurobehavioral changes among shipyard painters exposed to solvents. Arch Environ Health 40, 47-52.

23) Ruijten MW, Hooisma J, Brons JT, Habets CE, Emmen HH, Muijser H (1994) Neurobehavioral effects of longterm exposure to xylene and mixed organic solvents in shipyard spray painters. NeuroToxicol 15, 613-20.

24) Chen R, Dick F, Seaton A (1999) Health effects of solvent exposure among dockyard painters: mortality and neuropsychological symptoms. Occup Environ Med 56, 383-7.

25) Chen R, Wei L, Seaton A (1999) Neuropsychological symptoms in Chinese male and female painters: an epidemiological study in dockyard workers. Occup Environ Med 56, 388-90.

26) Sakong J, Chung JH (1994) Effects of organic solvents on computerized neurobehavioral test performance of the car painters. Korean J Prev Med 27, 487-504.

27) Chung JH, Kim CY, Sakong J (1994) Computerized neurobehavioral test of workers exposed to organic solvents. Korean J Occup Environ Med 6, 219-41.

28) Sakong J, Chung JH, Sung NK, Lee JJ, Park JT, Kim DS (2000) Assessment of neurobehavioral performance among welders exposed manganese. Korean J Occup Environ Med 12, 327-37.

29) Gamberale F, Iregren A, Kjellberg A (1989) SPES: The computerized Swedish performance evaluation system: Background, critical issues, empirical data and a users' manual. 1-77, National Institute of Occupational Health, Solna.

30) Anger WK (1990) Worksite behavioral research: results, sensitive methods, test batteries, and the transition from laboratory data to human health. NeuroToxicol 11, 629720.

31) ACGIH (2002) Documentation of the TLVs and BEIs with other worldwide occupational exposure values (CD-ROM 2002).

32) Letz R (1993) Covariate of computerized neurobehavioral test performance in epidemiologic investigations. Environ Res 61, 124-32.

33) Kang SK (2000) The applicability of WHO-NCTB in Korea. Neurotoxicology 21, 697-702.

34) Echeverria D, Fine L, Langolf G, Schork T, Sampaio $\mathrm{C}$ (1991) Acute behavioral comparisons of toluene and ethanol in human subjects. Br J Ind Med 48, 750-61.

35) Parker ES, Parker DA, Brody JA, Schoenberg R (1982) Cognitive patterns resembling premature aging in male social drinkers. Alcohol Clin Exp Res 6, 46-52.

36) Andersson K, Hockey RJ (1977) Effect of cigarette smoking on incidental memory. Psychopharmacologia 52, 223-6.

37) Letz R (1991) Use of computerized batteries for quantifying neurobehavioral outcomes. Environ Health Pers 90, 195-8.

38) Jeon MJ, Kim CY, Chung JH, Lim WT, Sakong J (2004) Effects of famiriality with computer and type of keyboard on computerized neurobehavioral performance tests. Korean J Occup Environ Med 16, 178-190.

39) Spurgeon A, Gray CN, Sims J, Calvert I, Levy LS, Harvey PG, Harrington JM (1992) Neurobehavioral effects of long-term occupational exposure to organic solvents: two comparable studies. Am J Ind Med 22, $325-35$. 